\title{
Progressive Development of Chiari I Malformation in a Child with Trilateral Retinoblastoma and Acquired Growth Hormone Deficiency
}

\author{
Todd Maugans $^{\mathrm{a}}$ Cristina Hochwalt ${ }^{\mathrm{a}} \quad$ Garbriella Gonzales $^{\mathrm{a}} \quad$ James Geller $^{\mathrm{b}}$ \\ Divisions of a Neurosurgery and ${ }^{\mathrm{b}} \mathrm{Hematology/Oncology,} \mathrm{Cincinnati} \mathrm{Children's} \mathrm{Hospital} \mathrm{Medical} \mathrm{Center,}$ \\ Cincinnati, Ohio, USA
}

A 3-month-old infant presented to our institution with a brief history of emesis and a full anterior fontanelle. MRI revealed acute hydrocephalus secondary to a $3-\mathrm{cm}$ suprasellar mass obstructing both foramina of Monro as well as bilateral retinal lesions; this was radiologically consistent with trilateral retinoblastoma. Subtotal resection of the intracranial mass and placement of bilateral ventriculoperitoneal shunts were carried out. He was enrolled in Children's Oncology Group protocol ARET 0321 (phase II clinical trial for extraocular retinoblastoma, stage IV protocol) and received cisplatin, cyclophosphamide, etoposide, and vincristine therapy with 3 intensive cycles followed by an autologous stem cell transplant. At 8 months of age a gross total resection of the residual suprasellar neoplasm was performed, and to date no recurrent disease has occurred. Complications of the suprasellar mass and its surgical extirpation included panhypopituitarism with a low growth hormone level $(1.9 \mathrm{ng} / \mathrm{ml})$ and insulin-like growth factor binding protein 3 level $(494 \mathrm{ng} / \mathrm{ml})$. Despite older literature asserting a non-deleterious effect [1], human growth hormone supplementation was not initiated due to a theoretical concern for regrowth of tumors. The patient currently experiences severe developmental and neurocognitive impairments; however, he has no focal neurological deficits beyond retinal blindness.

MRI scans for tumor surveillance have been performed according to COG protocol, approximately ev- ery 3-4 months, adjusted based on state of health. Beginning at 2 years of age, a progressive Chiari I malformation was revealed during the subsequent 24 months, with gradual descent of the cerebellar tonsils through the foramen magnum $(-2,2.4,4.1,10.8,11.6 \mathrm{~mm})$ (fig. 1a-e). The images also show abnormal growth of the basiocciput, as assessed by the methodology of Trigylidas et al. [2]. At 3.5 years of age, syringomyelia limited to the cervical spinal cord was observed (fig. 1e). At latest follow-up (4 years of age), the tonsillar descent and syrinx have stabilized without need for neurosurgical intervention. Clinical and radiological surveillance continues. Posterior fossa decompression will be offered if the patient demonstrates symptom development or syrinx enlargement.

Although the association between idiopathic growth hormone deficiency and Chiari I malformation in the pediatric population has been previously reported [2-6], this case uniquely demonstrates the relatively rapid evolution of a Chiari I malformation in a young child who acquired hypopituitarism during infancy, following successful treatment of a highly malignant neoplastic process. This child did not receive radiotherapy or chemotherapeutic agents known to affect the growth of the basiocciput. Therefore, we believe that this case provides visual confirmation of the role of acquired growth hormone deficiency in the development pediatric Chiari I malformation.

\section{KARGER}

Fax +4161306 1234 E-Mail karger@karger.ch www.karger.com

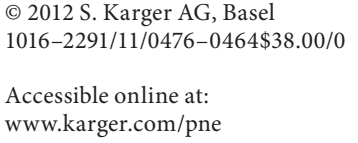

Todd Maugans, MD

Division of Neurosurgery

Nemours Children's Hospital

9145 Narcoossee Rd, Orlando, FL 32827 (USA)

E-Mail tmaugans@nemours.org 

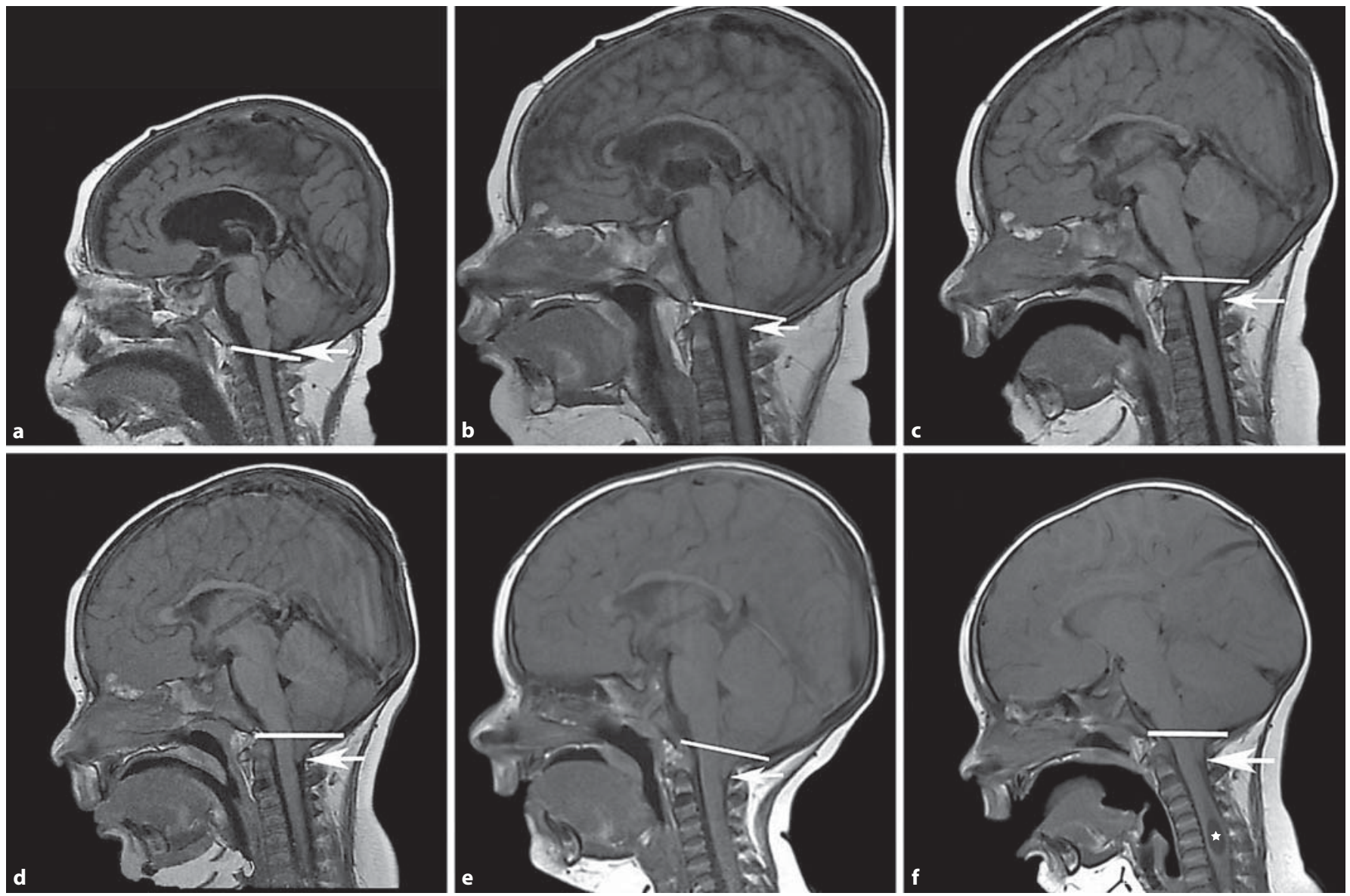

Fig. 1. $\mathrm{T}_{1}$-weighted midsagittal MRI scans revealing a progressive Chiari I malformation in a patient with acquired growth hormone failure following treatment for trilateral retinoblastoma with a suprasellar mass. The images illustrate the location of the cerebellar tonsillar tip (arrow) relative to the inferior margin of the foramen

magnum (basion-opisthion line) at various time intervals posttherapy: $2 \mathrm{~mm}$ above at 4 months (a); $2.4 \mathrm{~mm}$ below at 11 months (b); $4.1 \mathrm{~mm}$ below at 15 months (c); $10.8 \mathrm{~mm}$ below at 19 months (d); $11.6 \mathrm{~mm}$ below without syrinx at 24 months (e), and $11.6 \mathrm{~mm}$ below with cervical syrinx (star) at 30 months (f).

\section{References}

1 Arslanian SA, Becker DJ, Lee PA, Drash AL, Foley TP: Growth hormone therapy and tumor recurrence. Findings in children with brain neoplasms panhypopituitarism. Am J Dis Child 1985;139:347-350.

-2 Trigylidas T, Baronia B, Vassilyadi M, Ventureyra ECG: Posterior fossa dimension and volume estimates in pediatric patients with Chiari I malformations. Child Nerv Syst 2008;24:329-336.
-3 Murphy RL, Tubbs RS, Grabb PA, Oakes WJ: Chiari I malformation and idiopathic growth hormone deficiency in siblings. Childs Nerv Syst 2006;22:632-634.

4 Tubbs RS, Beckman J, Naftel RP, Chern JJ, Wellons JC 3rd, Rozzelle CJ, Blount JP, Oakes WJ: Institutional experience with 500 cases of surgically treated pediatric Chiari malformation type I. J Neurosurg Pediatr 2011;7: 248-256.
5 Tubbs RS, McGirt MJ, Oakes WJ: Surgical experience in 130 pediatric patients with Chiari I malformations. J Neurosurg 2003; 99:291-296.

6 Tubbs RS, Wellons JC 3rd, Smyth MD, Bartolucci AA, Blount JP, Oakes WJ, Grabb PA: Children with growth hormone deficiency and Chiari I malformation: a morphometric analysis of the posterior cranial fossa. Pediatr Neurosurg 2003;38:324-328. 